do 43; Perfil facial reto;; Dentes 18, 28, 38 e 48 por erupcionar. Análise cefalométrica: Classe I esquelética; Mesofacial. Plano de tratamento: Aparelho fixo superior e inferior; Exodontia do dente 53 e descruzar o dente 13; Exodontia do dente 48 e distalização do quarto quadrante até atingir classe I dentária com recurso a mini-implante; Contenções.

Discussão: A utilização de mini-implantes intra-alveolares, em especial entre as raízes, tem apresentado resultados satisfatórios na ancoragem absoluta; contudo, há o risco de lesão das raízes e o seu uso na correção da classe molar é limitada. Em alternativa aos métodos de ancoragem tradicionais, os mini-implantes Buccal Shelf oferecem a possibilidade de serem colocados numa região extra-alveolar mandibular, inseridos fora da arcada dentária, próximo dos molares, ao longo da linha oblíqua externa, permite o movimento em massa das arcadas dentárias sem risco de danificar as raízes. Existe outro tipo de ancoragem, as mini placas aplicadas no corpo da mandibula. Porém, apresentam a desvantagem de requererem uma cirurgia maior, com aplicação de vários parafusos de fixação; é necessária uma segunda cirurgia para a remoção das mini placas e apresentam custos mais elevados. Contudo têm mais estabilidade e suportam forças maiores.

Conclusões: Com o presente caso clinico concluímos que é possível obter resultados estéticos satisfatórios e estabilidade a longo prazo no tratamento de uma classe III dentária direita, recorrendo à distalização da hemi-arcada com mini-implante colocado na linha oblíqua externa (Buccal Shelf). http://doi.org/10.24873/j.rpemd.2018.11.405

\section{\#SPODF-10 Localização dos vetores produzidos pelo arco facial em relação aos centros de resistência}

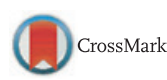

Mónica Amorim, Carlota Rey-Joly, Sara Palmares, Carolina Santos, Rui Pereira

Faculdade de Medicina Dentária da Universidade de Lisboa

Descrição dos casos: Foram selecionados pacientes da clínica pós-graduada de Ortodontia da Faculdade de Medicina Dentária da Universidade de Lisboa com indicação para tratamento com arco facial em combinação ou não com aparatologia fixa. No planeamento de cada caso foram executados registos fotográficos, modelos e exames complementares de diagnóstico (ortopantomografia e telerradiografia de perfil). Os traçados cefalométricos iniciais foram realizados recorrendo ao software NemoCeph (Nemotec, Madrid, Espanha). Durante a consulta de aplicação da tração extra-oral, foram realizados novos registos fotográficos extra-orais de perfil com o arco facial colocado. As fotografias foram então descarregadas para o software de modo a efetuar a sobreposição com a teleradiografia de perfil. A alteração da transparência da fotografia em relação à telerradiografia permitiu identificar a relação da linha de força com o centro teórico de resistência e a sua correspondência ao clinicamente desejado. Deste modo, as respetivas correções podem ser aplicadas de forma consistente.

Discussão: O método descrito permite obter, de forma precisa e não invasiva, os vetores de força adequados ao objetivo pretendido. Embora a discussão teórica das forças e vetores dos arcos faciais esteja amplamente debatida na bibliografia ortodôntica, a sua aplicação clínica reflete-se geralmente numa colocação pouco rigorosa, tanto em relação à força utilizada como em relação ao vetor. A utilização de dinamómetros ou de molas de níquel-titânio calibradas permite ultrapassar o primeiro ponto, mas a identificação da relação dos vetores com os centros de resistência teóricos não é avaliada de uma forma precisa.

Conclusões: Recorrendo a software de traçado cefalométrico, a sobreposição da telerradiografia inicial com fotografias de perfil de arco facial colocado permite aplicar o sistema de forças desejado de forma prática e precisa.

http://doi.org/10.24873/j.rpemd.2018.11.406

\#SPODF-11 Tratamento ortodôntico da agenesia dos incisivos laterais com compressão maxilar

Fred Pinheiro, Jorge Dias Lopes, André Afonso, Sofia Jerónimo, Luis Bessa

Faculdade Medicina Dentária da Universidade do Porto; Iron

Descrição do caso clínico: A paciente do género feminino, 13 anos compareceu à consulta de ortodontia de uma clínica privada. De ponto de vista ortodôntico a paciente apresentava uma compressão maxilar com mordida cruzada unilateral esquerda inserida num padrão esquelético tipo classe II com distoclusão molar e agenesia dos incisivos laterais. Como plano de tratamento foi proposto uma expansão rápida da maxila para correção do problema transversal, posteriormente colocação de aparelho ortodôntico fixo bimaxilar para reposicionar os dentes caninos e pré-molares e como finalização a reanatomização destes dentes de forma a garantir uma boa estética dentária e função.

Discussão: Apesar das diferenças anatómicas o ortodontista tem a possibilidade de camuflar a ausência dos incisivos laterais colocando os caninos numa posição periodontal e oclusal bastantes satisfatórias de forma que a prostodontia possa devolver a anatomia ideal das peças dentárias substituídas.

Conclusões: A camuflagem ortodôntica pode uma apresentar-se como uma excelente opção garantindo ao paciente uma estética e função naturais sem recurso a métodos mais invasivos.

http://doi.org/10.24873/j.rpemd.2018.11.407

\#SPODF-12 Mini-placas para ancoragem esquelética temporária: Colocação cirúrgica

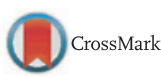

Margarida Nunes, Luís Bessa, Fred Pinehiro, Inês Correia, Eugénio Martins

Curso de Especialização em Ortodontia da FMDUP; Pós-graduado em Cirurgia Ortognática pela Associação Brasileira de Cirurgia Crânio-maxilo-facial; Professor Auxiliar da FMDUP.

Introdução: Os sistemas de ancoragem esquelética temporária, tais como as mini-placas, permitem a obtenção de ancoragem máxima. As mini-placas apresentam a vantagem 